\title{
Estrutura de capital: uma revisão bibliográfica das publicações dos periódicos nacionais
}

Capital structure: a literature review of publications of national journals

Estructura de capital: una revisión bibliográfica de las publicaciones de los periódicos nacionales

\section{Wanderson Rocha Bittencourt}

Doutorando em Administração na Universidade de Brasília - UNB

Professor dos cursos de Administração e Contabilidade - UniCeub

Endereço: Ap. 202, Bloco K, UnB - Colina, Asa Norte.

CEP: 70904-111, Brasília - DF, Brasil

E-mail: wandersonrochabittencourt@gmail.com

Telefone: + 55 (031) 9 9982-1563

\section{Pedro Henrique Melo de Albuquerque}

Doutor em Administração na Universidade de Brasília - UNB

Professor da Universidade de Brasília - UNB

Endereço: Campus Universitário Darcy Ribeiro - Prédio da Faculdade de Economia, Administração e Contabilidade (FACE) - Bloco A-2, $1^{\circ}$ andar - Sala A1-54/7 - Asa Norte Brasília, Distrito Federal

CEP: 70910-900, Brasília - DF, Brasil

E-mail:pedroa@unb.br

Telefone: +55 (061) 3107-0837

Artigo recebido em 10/07/2016. Revisado por pares em 14/07/2017. Reformulado em 11/10/2017. Recomendado para publicação em 08/03/2018 por Carlos Eduardo Facin Lavarda (Editor-Chefe). Publicado em 28/03/2018. 


\title{
Resumo
}

A estrutura de capital está sendo estudada profundamente desde os trabalhos de Modigliani e Miller (1958 e 1963). Neste contexto, os pesquisadores vêm buscando explicar a utilização das mais diversas estruturas de capital utilizadas e suas aplicações. Assim, esta pesquisa busca identificar como está sendo pesquisada a estrutura de capital em periódicos nacionais. Para tal, foi realizado um levantamento bibliométrico na base Periódicos Capes com os termos estrutura de capital e estrutura da dívida, no título ou palavras-chave. Foram encontrados, ao todo, 80 artigos. De maneira geral, os resultados dos trabalhos apontaram que as empresas brasileiras tendem a adotar uma estrutura de capital baseada na hierarquia de fontes de financiamento. Contudo, na presença de incentivos governamentais, possivelmente, as teorias não seriam aplicadas. Diante da diversidade de variáveis empregadas nos trabalhos foram propostas algumas categorias a serem incorporadas nos modelos, tais como: tamanho, tangibilidade, rentabilidade, gestão, risco, macroeconômico e alavancagem.

Palavras-chave: Estrutura de capital; Estrutura da dívida; Bibliometria

\begin{abstract}
The capital structure is being studied deeply from the works of Modigliani and Miller (1958 and 1963). In this context, researchers have been trying to explain the use of several used capital structures and their applications. Thus, this research seeks to identify as being searched capital structure in national journals. To do this, a bibliometric survey on the basis Portal Periodicos Capes with the terms of capital structure and debt structure was carried out in the title or keywords. Was found in all, 80 articles. Overall, the results of the work showed that Brazilian companies tend to adopt a capital structure based on funding sources hierarchy. However, in the presence of government incentives, possibly theories would not be applied. Given the diversity of variables used in the work were proposed some categories to be incorporated in the models, such as size, tangibility, profitability, management, risk, macroeconomic and leverage.
\end{abstract}

Keywords: Capital structure; Debt structure; Bibliometrics

\section{Resumen}

La estructura de capital está siendo estudiada profundamente desde los trabajos de Modigliani y Miller (1958 y 1963). En este contexto, los investigadores han buscado explicar el uso de las más diversas estructuras de capital utilizadas y sus aplicaciones. Así, esta investigación busca identificar cómo está siendo estudiada la estructura de capital en Revistas nacionales. Para ello, se realizó un levantamiento bibliométrico en la base de datos Periódicos Capes con los términos estructura de capital y estructura de la deuda, presentes en el título o en las palabras llave. Fueron encontrados, un total de 80 artículos. En general, los resultados de los trabajos apuntaran a que las empresas brasileñas tienden a adoptar una estructura de capital basada en la jerarquía de fuentes de financiamiento. Sin embargo, en presencia de incentivos gubernamentales, hará que posiblemente las teorías no sean aplicables. Frente a la diversidad de variables empleadas en los trabajos se proponen algunas categorías a ser incorporadas en los modelos, tales como: tamaño, tangibilidad, rentabilidad, gestión, riesgo, macroeconómico y apalancamiento.

Palabras clave: Estructura de capital; Estructura de la deuda; Bibliometría

\section{Introdução}

A estrutura de capital vem sendo pesquisada ao longo dos anos, com maior enfoque a partir dos trabalhos seminais de Modigliani e Miller $(1958,1963)$ na qual os autores partem de 
uma situação hipotética e constroem um modelo que explique a estrutura de capital das empresas sem a presença de impostos. No segundo artigo os autores reconsideram os benefícios dos impostos na estrutura de capital.

A partir dos pressupostos de Modigliani e Miller a teoria referente à estrutura de capital da empresa ganhou novos incentivos. Vickers (1970) estudou a otimização do custo do capital para as empresas, e foi identificado que este custo está ligado as decisões de otimização tomada internamente, tais como fatores de produção. Foi introduzida também a ideia de assimetria de informação referente às transações nas quais os agentes atuantes possuíam informações privilegiadas, e quanto a assimetria informacional pode influenciar o equilíbrio de mercado (AKERLOF, 1970). Ainda neste âmbito, foi estudado por Myers e Majluf (1984) o quanto assimetria de informação influencia a estrutura de capital e a emissão de ações.

Myers (1984) procurou explicar a estrutura de capital a partir de duas teorias: a primeira chamada de Static Tradeoff Theory (STT), na qual a empresa estipula uma meta de endividamento e busca alcança-la, e a segunda, conhecida como Pecking Order Theory (POT), na qual a empresa segue uma ordem hierárquica para estabelecer a sua estrutura de capital.

Mais recentemente, Rajan e Zingales (1995) construíram um modelo partindo do pressuposto de que as empresas têm uma tendência de buscarem um nível ótimo de endividamento, o qual seria atendido caso não houvesse assimetria de informação e custos de transação. Outro modelo que propõe explicar a estrutura de capital foi formulado por Frank e Goyal (2003) na qual encontraram como um dos principais determinantes da estrutura de capital a rentabilidade dos ativos.

Contudo, ressalvas devem ser tomadas, já que estes diversos modelos foram desenvolvidos no contexto da economia norte-americana, (MEDEIROS; DAHER, 2008), em que existe maior estabilidade econômica. Tais contribuições, são úteis para estudar estas teorias no cenário nacional, já que está próximo de 60 anos de uma das principais contribuições acadêmicas para a área de finanças corporativas. No decorrer dos anos, pesquisadores brasileiros (POHLMANN et al., 2004; TERRA, 2007; MACHADO; MEDEIROS; EID JÚNIOR, 2010; MACHADO; GODOY, 2013) testaram tais teorias nos mais diversos cenários. A partir de então, muitas contribuições têm aparecido.

Apesar disso, com a diversidade de instituições, Myers (1984) advertiu que um modelo geral e único de estrutura de capital tomaria contornos gigantescos e complexos. Uma proposta colocada por Myers (1984) seria a busca por uma estrutura buscando uma formulação de modelagens particulares, captando as necessidades e especificidades de cada setor, por exemplo. Assim, se existe uma estrutura ótima de capital ainda é uma incógnita, contudo, vem sendo analisada constantemente pelos trabalhos, tanto internacionais como nacionais. Neste contexto, esta pesquisa busca identificar como está sendo pesquisada a estrutura de capital em periódicos nacionais, bem como levantar as principais variáveis e modelos utilizados nos estudos.

Cabe destacar que este trabalho não tem por característica descrever, exaustivamente, as teorias que permeiam a estrutura de capital e sim a preocupação é demonstrar a evolução da temática no contexto nacional e apresentar um pouco sobre correntes teóricas da estrutura de capital, a Peking Order Theory - POT e a Static Tradeoff Theory - (STT). Apresenta, também, como contribuição um levantamento das diversas variáveis utilizadas na literatura nacional, bem como algumas das metodologias mais utilizadas e algumas das propostas apresentadas pelos trabalhos pesquisados para tratar dos problemas de endogeneidade e causalidade.

Além da introdução, na segunda seção é discutida as principais teorias a respeito da estrutura de capital. Na terceira seção é apresentada a metodologia da pesquisa. Na quarta seção a análise dos dados e por fim as considerações finais. 


\section{Referencial teórico}

Com o objetivo de ampliar o entendimento das teorias de estrutura de capital, o referencial teórico foi segregado em quatro subtópicos. No primeiro é abordada a estrutura de capital clássica a partir dos trabalhos de Modigliani e Miller. No segundo são apresentadas algumas colocações sobre a Peking Order Theory - POT. No terceiro são destacados os principais constructos pertinentes a Static Tradeoff Theory - (STT). E, por fim, algumas considerações sobre pontos convergentes e divergentes das teorias.

\subsection{Estrutura de capital - teoria clássica de Modigliani e Miller}

A estrutura de capital das empresas refere-se à origem dos recursos utilizados, trata-se de uma combinação entre as dívidas de curto, médio e longo prazo e capital próprio. Esta estrutura evidencia o esforço das firmas em gerar resultados diante do capital empregado, ou seja, a estrutura de capital é a escolha da fonte de financiamento de maneira a maximizar os resultados dos investidores (MYERS, 1977, 1984; MYERS; MAJLUF, 1984). Em outras palavras, a estrutura de capital refere-se à composição do financiamento, capital próprio ou de terceiros, sendo este último de curto e longo prazo, na qual os gestores tendem a escolher a melhor opção entre utilizar pequena ou grande parte deste capital, para financiar suas atividades.

O estudo da estrutura de capital das empresas ganhou destaque a partir do final da década de 1950 com os trabalhos de Modigliani e Miller (1958, 1963). Os autores partem de uma situação hipotética sem a presença de impostos, logo após, é estudado separadamente os benefícios de impostos e seus efeitos na estrutura de capital. Deste modo, foi mostrado que a política de financiamento de uma empresa não afeta seu valor de mercado. Contudo, com a inserção dos impostos e a probabilidade de falência, a alavancagem financeira resultaria em menor taxa de desconto e maior valor para a empresa. Esta vertente se sustenta até certo ponto, pois, com o aumento da dívida, além de um determinado ponto, a probabilidade de falência aumenta e gera a perda de benefícios fiscais, resultando em maior taxa de desconto e menor valor para a empresa.

Modigliani e Miller (1958) destacaram, também, que a opção de compra de ativos só se torna vantajosa para a empresa, somente se esta aumentar o lucro líquido acima dos retornos esperados, ou seja, exceder a taxa de juros. Outra avaliação ao comprar um ativo seria se este geraria um aumento de capital para os proprietários maior que o seu custo de aquisição. Estas suposições levaram os autores a concluírem que o retorno de um ativo é igual à taxa de juros dos títulos de mercado.

Desta forma, os fatores determinantes da estrutura de capital, restritos a aspectos internos da firma, tais como: nível de tangibilidade, tamanho, rentabilidade, risco, oportunidade de crescimento, dívidas de longo prazo, nível de imposto de renda, benefícios fiscais e composição dos ativos podem influenciar a estrutura de capital.

A assimetria de informação também influencia a estrutura de capital (AKERLOF, 1970). Esta assimetria poderia ser causada, em parte, pela política de dividendos e o seu pagamento ou não, sinalizando ao mercado que a empresa possui uma estrutura sólida (MATOS, 2001). Dependendo da postura adotada pelos gestores, ao escolher a estrutura de capital da empresa, esta pode ficar mais ou menos alavancada, ou seja, pode depender de maior ou menor participação de capital de terceiros, como forma de financiamento.

Bae, Kang e Wang (2011) e Matos (2001) destacaram que interessados externos a empresa, tais como fornecedores, cliente e trabalhadores podem ter influência significativa sobre a estrutura de capital. Os autores argumentam que as partes interessadas enfrentam custos 
de mudanças se a empresa for liquidada. Com esta prerrogativa, os incentivos a investimentos dependem da condição financeira da empresa.

\subsection{Teoria da Peking Order - POT}

A Peking Order Theory - POT foi proposta inicialmente por Myers e Majluf (1984). Os autores pressupõem que no mercado existe a presença da assimetria da informação que afeta diretamente a escolha entre o financiamento interno e externo e a emissão de títulos de dívidas ou de ações. Isso remete à ideia de uma hierarquia de fontes de financiamento.

Nesta teoria, não existe uma estrutura alvo que combine capital próprio e de terceiros. As empresas adotam uma hierarquia preferencial para as fontes de financiamento, buscando maximizar os interesses tanto da administração quanto dos acionistas. Os gestores tendem a decidir uma forma de financiamento para as atividades empresariais e, a partir daí, analisam as diversas fontes de recursos e tendem por financiamento interno. Para tal, existe, também, a possibilidade de ajustes na distribuição de dividendos às oportunidades de investimento. Caso não seja suficiente, a empresa começa a sacar saldo em caixa ou a vender sua carteira de títulos negociáveis (BREALEY; MYERS; ALLEN, 2011).

Caso a empresa necessite de recursos externos, começa pela dívida, depois emite títulos híbridos, emissão de debêntures e títulos conversíveis, antes da opção da emissão de ações (MYERS; MAJLUF, 1984). Para esta última opção, a emissão de novas ações, haveria uma relutância dos gestores, principalmente, por existir a possibilidade de subprecificação das ações pelo mercado, já que indicaria a divergência de informação entre os gestores e o mercado em relação aos ativos e os fluxos esperados.

O mercado entenderia que a empresa buscaria recursos na emissão de ações, uma vez que o seu fluxo de caixa interno não seria suficiente para financiar suas atividades. Assim, a preferência por recursos internos seria fundamentada, ainda mais na premissa de que tais recursos não possuem custos de transação (MYERS, 1984). Com isso, a POT explica porque grande parte do financiamento de empresas menos rentáveis é derivada de emissões de dívidas e porque as empresas mais lucrativas são menos endividadas.

Esta hierarquia explica o motivo das empresas menos lucrativas geralmente adquirem dívida, por não dispor de fundos internos suficientes para financiar o seu plano de investimento, e o motivo do financiamento por dívida está em primeiro lugar na hierarquia das fontes de financiamento externo (BREALEY; MYERS; ALLEN, 2011). Tem-se então, que na POT, a alavancagem financeira varia negativamente com os fundos gerados internamente, representado, principalmente, pela liquidez dos ativos, rentabilidade e liquidez dos dividendos.

\subsection{Teoria Static Tradeoff Theory - (STT)}

Proposta por Myers (1984), a Static Tradeoff Theory - (STT) defende que as empresas busquem uma estrutura de capital ótima, visando à maximização dos benefícios para os acionistas e, consequentemente, reduza os custos de endividamento. $\mathrm{O}$ autor assume que os administradores das empresas estabelecem uma meta para o endividamento e ajustam constantemente a estrutura de capital da empresa, buscando atingi-la. Esta meta é determinada como sendo um valor ótimo, resultante dos benefícios fiscais e custos incorridos no caso de falência.

Contudo, esta meta de endividamento varia de empresa para empresa. As empresas com ativos tangíveis, seguros e com elevados rendimentos tributáveis, na qual é possível obter benefícios fiscais, deveriam elevar o volume de endividamento. Já as empresas pouco rentáveis, com ativos intangíveis arriscados, deveriam se basear, principalmente, em capital próprio 
(BREALEY; MYERS; ALLEN, 2011), já que com estas suposições, as despesas com juros são dedutíveis dos impostos, enquanto os dividendos não são, além de maiores garantias junto ao mercado. Esta teoria corrobora, pelo menos em parte, com as colocações de Modigliani e Miller (1963) na qual indicava o endividamento máximo das empresas.

Assim, com base na STT, as empresas ajustam os pagamentos de dividendos visando atingir as suas metas de remuneração, buscando, paralelamente, o melhor nível de endividamento. Outra medida colocada por Myers (1984) seria a redução dos pagamentos em períodos de crise financeira, principalmente para empresas pouco lucrativa e alavancada. Contudo, caso não existisse custos de mudança da estrutura de capital, as empresas sempre se posicionariam em um determinado índice de endividamento. Porém, na presença de tais custos, há atrasos nos ajustamentos e as empresas perseguem este nível de endividamento ótimo.

Myers (1984) também propõe que mantido constantes os valores de investimentos e ativos da empresa, o limite para o uso do capital de terceiros se dá quando os custos gerados pelos investimentos são maiores do que os benefícios gerados pela economia fiscal.

De maneira geral, a teoria tradeoff consegue explicar satisfatoriamente muitas diferenças existentes entre as estruturas de capital entre os diversos setores. Empresas que empregam alta tecnologia, em que os ativos apresentam elevados índices de riscos, normalmente intangíveis, utilizam, normalmente, pouca dívida (BREALEY; MYERS; ALLEN, 2011).

Tem-se, então, como principais variáveis capazes de influenciar o endividamento, de acordo com a teoria tradeoff: a tangibilidade dos ativos e o lucro, sendo que estão positivamente relacionadas com a alavancagem financeira.

\subsection{Considerações sobre estrutura de capital, a teoria de Modigliani e Miller, tradeoff e peking order}

A ideia geral proposta por Modigliani e Miller indica que as empresas devem buscar o endividamento ao máximo, já que as despesas com juros são deduzidas das bases tributárias ao contrário de outras fontes de financiamento. Contudo, foi advertido que este endividamento deve ser analisado com parcimônia, pois, segundo a STT a tangibilidade dos ativos e o lucro da empresa influencia positivamente a opção pela alavancagem financeira. Dentro de uma preferência por endividamento, POT, a alavancagem financeira é influenciada pelos fundos gerados internamente, rentabilidade e liquidez dos dividendos.

Comparando a teoria do tradeoff e a peking order, Rajan e Zingales (1995) constataram que os índices de endividamentos das empresas do Canadá, França, Alemanha Itália, Japão, Reino Unido e Estados Unidos dependem de quatro fatores principais: o tamanho - em que as grandes empresas tendem a ter índices de endividamento maiores; tangibilidade dos ativos empresas com maiores índices de ativos tangíveis em relação ao ativo total têm índices de endividamento maiores; lucratividade - empresas com maior lucratividade apresentam menores índices de endividamento; e valor de mercado-valor contábil (índice interpretado como oportunidade de crescimento, em que as empresas em crescimento poderiam ter custos mais elevados associados às dificuldades financeiras) empresas com valor de mercado-valor contábil maior tende a ter endividamentos menores.

Estes resultados contribuem com as duas teorias - tradeoff e a peking order - já que empresas com maiores volumes em ativos tangíveis estão menos expostas a dificuldades financeiras. Aos que defendem a peking order existe a importância da lucratividade, e as empresas recorrem menos ao endividamento, pois podem confiar no autofinanciamento.

Outra possibilidade para os índices de endividamento seria o momento do mercado market-timing. Neste contexto, empresas que apresentam histórico de flutuações dos preços das 
suas ações tenderão e emitir ações, em períodos em que os preços estão em alta, e títulos de dívidas, quando os preços das ações estiverem em baixa. Este momento de mercado pode explicar por que as empresas tendem emitir ações depois de seus preços elevarem no mercado (BREALEY; MYERS; ALLEN, 2011).

\section{Metodologia}

Para esta pesquisa foi realizado um levantamento bibliográfico dos artigos relacionados à estrutura de capital. Segundo Gil (2008) a pesquisa bibliográfica é desenvolvida com base em material já elaborado, constituído principalmente de livros e artigos científicos. A principal vantagem da pesquisa bibliográfica reside no fato de permitir ao investigador a cobertura de uma gama de fenômenos muito mais ampla do que poderia pesquisar diretamente. O princípio da bibliometria é de explorar a atividade científica ou técnica através de estudos quantitativos das produções.

Para a busca e seleção dos artigos foi utilizada a base Periódicos Capes indexadora de mais de 31 mil títulos de artigos, nacionais e internacionais, nas mais diversas áreas, que reúne artigos que passaram por um processo de revisão por pares, sendo uma base de dados com textos completos de revistas selecionadas (CAPES, 2017). Este indexador fornece informações dos artigos originais, para facilitar a localização do material de interesse sem que seja necessário procurar todos os periódicos da área em questão. Essas informações incluem, usualmente: autor, título do artigo, título do periódico, International Standard Serial Number - ISSN (Número Internacional Normalizado para Publicações Seriadas, refere-se ao código aceito internacionalmente para o título de um periódico seriado), ano, volume e/ou número do fascículo e número de páginas.

Foram utilizadas duas palavras-chave para as buscas dos artigos, a saber: Estrutura de capital e estrutura da dívida. Estes dois termos são, de maneira mais ampla, a essência da teoria, já que tais termos abrangem um conjunto de subteorias, definições e indicadores financeiros adotados na literatura, além de serem os temos mais usuais nas principais literaturas (HARRIS; RAVIV, 1991; MATOS, 2001; MODIGLIANI; MILLER, 1963; MYERS, 1977, 1984; MYERS; MAJLUF, 1984).

Com a inserção do termo Estrutura de Capital no campo de busca da base, obteve-se como retorno 201 resultados. Foram excluídos os resultados que não possuíam revisão por pares, restando 94 artigos. Foram selecionados artigos que apresentavam o termo estrutura de capital no título e nas palavras-chave dos artigos. Entende-se que o título e as palavras-chave do artigo representam e refletem a essência do trabalho (SERRA; FERREIRA, 2014). Após este processo foi pesquisado o termo Estrutura da Dívida, retornando 133 resultados e após a seleção de trabalhos revisados por pares restaram 45. Após todos estes processos, e retiradas às duplicidades, foram selecionados 80 artigos. Cabe destacar que o período final da busca foi o mês de maio de 2016.

\subsection{Segmentação dos artigos}

Para a análise foram coletadas informações sobre: autor(res), título, ano de publicação, segmento de aplicação, identificação do periódico - ISSN, analisada a classificação Webqualis, de acordo com a classificação do ano de 2015, palavras-chave, natureza do artigo, fundamentos teóricos, período de aplicação do estudo, recorte temporal, métodos/modelos, origem dos dados, variáveis utilizadas, setores pesquisados, instrumentos de coleta de dados.

Para o melhor mapeamento das pesquisas foram adotadas algumas dimensões para a análise. A primeira refere-se à identificação e demografia da produção. A segunda refere-se à 
metodologia. A terceira categoria apresenta as principais variáveis empregadas nos artigos. Por fim, as principais conclusões das pesquisas analisadas.

A segmentação demográfica apresenta o grau de escolaridade dos autores, quantidade de referência, além dos periódicos publicados. Quanto ao quesito referências utilizadas, buscouse verificar com maior profundidade a origem dos fundamentos incorporados às produções, fragmentando em livros, artigos nacionais e internacionais, eventos nacionais, teses e dissertações e outros nacionais e internacionais. No que tange a classificação dos períodos pesquisados, busca-se identificar o quanto os pesquisadores estão publicando em periódicos mais consolidados, classificados nos extratos superiores segundo a classificação webqualis do ano de 2015.

Quanto à segmentação metodológica, os textos foram classificados quanto à natureza, fundamentos teóricos utilizados, abordagem e recorte de pesquisa, método de pesquisa, amostraram e modelos utilizados além das principais variáveis dependentes e independentes utilizadas. No que tange à natureza do artigo foram adotadas as categorias: teórico, artigos que apresentavam iniciativas de revisão e/ou discussão de teorias, modelos, conceitos ou proposição de novas teorias, e teórico-empírico, estudos que buscavam testar a relação entre variáveis de modo controlado ou não (estudos experimentais, ou quase experimentais), ou não (estudos correlacionais), ou descrever o comportamento de determinadas variáveis.

Abordagem foi classifica em qualitativa, quantitativa e mista. Conforme Appolinário, (2009), a abordagem quantitativa tem como princípio a mensuração e quantificação dos dados e a qualitativa vem da participação de forma dinâmica, particular, contextual e temporal do pesquisador com o objeto de estudo. Já a abordagem mista seria utilização conjunta das duas.

$\mathrm{O}$ recorte temporal foi classificado como transversal (diversas empresas em mesmo ponto no tempo), longitudinal - (mesma empresa ao longo do tempo), misto (combinação entre transversal e longitudinal) (WOOLDRIDGE, 2002). Caso os trabalhos não apresentem recorte temporal (trabalhos somente teóricos) será classificado como não se aplica este tipo de recorte. Já as métricas de amostragem foram classificadas em probabilísticas e não probabilísticas (GIL, 2008). Caso o trabalho não tenha amostra será classificado como não apresentaram amostragem na pesquisa. Foi realizado também um levantamento das diversas ferramentas estatísticas (modelos) utilizadas nas pesquisas bem como as variáveis utilizadas.

\section{Análise dos dados}

Como mencionado, este artigo foca em quatro dimensões: identificação e segmentação demográfica, tipificação metodológica, variáveis estudadas e principais resultados dos artigos analisados. Nas duas primeiras seções são expostos os resultados dos 80 artigos analisados nas duas seguintes, algumas das principais contribuições em termos de variáveis utilizadas e resultados encontrados.

\subsection{Identificação e segmentação demográfica}

O primeiro trabalho publicado, de acordo com os filtros de seleção, foi em 1980. Até o ano de 2007, somente 17 trabalhos foram publicados, correspondendo a $21,25 \%$, ou seja, quase 50 anos após o trabalho de Modigliani e Miller ser publicado. Tal temática ganhou destaque no ano de 2009, com 17 publicações, fato este que pode ter ligeira relação com a crise financeira que ocorreu no ano de 2008. Desde então, tem-se, em média, cinco trabalhos publicados anualmente.

No que diz respeito à identificação demográfica dos artigos, Tabela 1, estes utilizam em sua maioria $(55,56 \%)$ artigos internacionais, que possuem elevado fator de impacto 
(classificação mais elevada no webqualis). As publicações em periódicos nacionais, Tabela 2, representaram 9,11\% das referências citadas. Estes resultados indicam que as pesquisas publicadas em periódicos nacionais possuem congruência com bases teóricas internacionais que, ao todo, representam $79,75 \%$ das referências. Outro ponto importante é a baixa quantidade de outras publicações nacionais $(3,76 \%)$, que por característica não possui um processo de revisão por pares, que são utilizadas, geralmente inclui: sites, leis, decretos, deliberações, work papers, revistas não científicas (Exame), revista do Banco Nacional de Desenvolvimento Social - BNDES, normas de contabilidade, monografias de graduação e pós-graduação (Lato Sensu), relatórios anuais do Instituto Brasileiro de Geografia e Estatística - IBGE e banco de dados como Economática. Já outras publicações internacionais referem-se a conferências, congressos, work papers e teses.

Tabela 1: Titulação dos autores

\begin{tabular}{|c|c|c|}
\hline Titulação & Total & $\%$ \\
\hline Doutor & 92 & $45,32 \%$ \\
\hline Doutorando & 16 & $7,88 \%$ \\
\hline Mestre & 31 & $15,27 \%$ \\
\hline Mestrando & 10 & $4,93 \%$ \\
\hline Graduado & 3 & $1,48 \%$ \\
\hline Graduando & 1 & $0,49 \%$ \\
\hline Não informado & 50 & $24,63 \%$ \\
\hline Total & 203 & $100,00 \%$ \\
\hline
\end{tabular}

Fonte: Dados da pesquisa.
Tabela 2: Referências utilizadas nas pesquisas

\begin{tabular}{lrr}
\hline Referências utilizadas & Total & $\mathbf{\%}$ \\
\hline Livros Nacionais & 240 & $8,93 \%$ \\
\hline Artigos Nacionais & 245 & $9,11 \%$ \\
\hline Outros nacionais & 101 & $3,76 \%$ \\
\hline Eventos nacionais & 148 & $5,50 \%$ \\
\hline Teses e dissertações & 79 & $2,94 \%$ \\
\hline Artigos internacionais & 1494 & $55,56 \%$ \\
\hline Livros Internacionais & 216 & $8,03 \%$ \\
\hline Outros internacionais & 166 & $6,17 \%$ \\
\hline Total & $\mathbf{2 6 8 9}$ & $\mathbf{1 0 0 \%}$ \\
\hline
\end{tabular}

Fonte: Dados da pesquisa.

Ainda no que tange ao consumo de referências utilizadas (média de 34/artigo), pode-se ainda afirmar que para cada artigo nacional utilizado seis internacionais são citados. Estes dados abrem espaço para hipóteses que poderão ser pesquisadas a respeito da qualidade e/ou profundidade teórico/empírica dos trabalhos produzidos nacionalmente. Outro ponto de possível argumento seria o maior acesso e especialização dos veículos de disseminação da produção científica desta temática. Contudo, não foi objetivo desta pesquisa identificar se os trabalhos citados são clássicos da literatura, justificando assim, pelo menos em parte, a suas utilizações.

Outro ponto a ser destacado é a elevada escolaridade dos pesquisadores. Dentre os artigos alisados, $44,33 \%$ dos pesquisadores tem doutorado concluído e mais $7,88 \%$ em andamento, indicando um possível amadurecimento das pesquisas, em virtude da elevada titulação dos pesquisadores. Cabe destacar ainda que em 31,25\% dos artigos não foi possível identificar tal informação, devido a alguns artigos não dispunham de dados de titulação. Com estes resultados especula-se ainda que a maioria da produção referente a estrutura de capital é oriunda de parcerias estabelecidas entre docentes e discentes de programa de pós-graduação.

No que tange a disseminação das pesquisas referentes à temática estrutura de capital, está predominante nos periódicos classificados no Webqualis mais elevado, revistas - A2, com $45,1 \%$, como pode ser observado na Tabela 3 .

Outro resultado relevante é que $20 \%$ dos artigos foram publicados na Revista de Contabilidade e Finanças, fator este que pode ser explicado pela sua especialização na área financeira. Contudo, outras revistas também especializadas em finanças como a Revista Brasileia de Finanças e a Brazilian Finance Review apresentaram, respectivamente, 3,9\% e $1,3 \%$ das produções com a temática estrutura de capital, indicando a preferências dos autores por revistas mais bem ranqueadas no Webqualis. Suposições para tal preferência pode ser a 
pontuação para avaliação e classificação dos cursos de pós-graduação pela a Capes, bem como pontuação individual do pesquisador que desenvolveu a pesquisa.

Tabela 3: Classificação Webqualis das revistas e total de artigos por revista

\begin{tabular}{|c|c|c|c|c|c|}
\hline Revistas classificadas como $\mathbf{A 2}^{\mathrm{a}}$ & Total & $\%$ & Revistas classificadas como B2 & Total & $\%$ \\
\hline Revista Contabilidade e Finanças & 16 & $20,0 \%$ & Pesquisa Operacional (Impresso) & 1 & $1,3 \%$ \\
\hline $\begin{array}{l}\text { Revista de Administração } \\
\text { Contemporânea }\end{array}$ & 8 & $10,0 \%$ & $\begin{array}{l}\text { Revista Brasileira de Finanças } \\
\text { (Impresso) }\end{array}$ & 3 & $3,9 \%$ \\
\hline Revista de Administração Eletrônica & 6 & $7,5 \%$ & Brazilian Finance Review - RBFin & 1 & $1,3 \%$ \\
\hline $\begin{array}{l}\text { Revista de Administração (FEA- } \\
\text { USP) }\end{array}$ & 3 & $3,9 \%$ & $\begin{array}{l}\text { Revista Iberoamericana de } \\
\text { Estratégia }\end{array}$ & 1 & $1,3 \%$ \\
\hline $\begin{array}{l}\text { Revista Brasileira de Gestão de } \\
\text { Negócios (Impresso) }\end{array}$ & 1 & $1,3 \%$ & $\begin{array}{l}\text { Revista Portuguesa e Brasileira de } \\
\text { Gestão }\end{array}$ & 1 & $1,3 \%$ \\
\hline Cadernos EBAPE.BR (FGV) & 1 & $1,3 \%$ & & & \\
\hline Total & 36 & $45,1 \%$ & Total & 7 & $8,8 \%$ \\
\hline Revistas classificadas como B1 $^{a}$ & Total & $\%$ & Revistas classificadas como B3 & Total & $\%$ \\
\hline Brazilian Business Review & 1 & $1,3 \%$ & Contextus (Fortaleza) & 1 & $1,3 \%$ \\
\hline Contabilidade Vista e Revista & 3 & $3,8 \%$ & $\begin{array}{l}\text { Pretexto (Belo Horizonte. } \\
\text { Impresso) }\end{array}$ & 1 & $1,3 \%$ \\
\hline Gestão e Produção (Impresso) & 2 & $2,5 \%$ & REGE. Revista de Gestão USP & 6 & $7,5 \%$ \\
\hline Revista de Administração Mackenzie & 8 & $10,0 \%$ & Revista de Finanças Aplicadas & 1 & $1,3 \%$ \\
\hline $\begin{array}{l}\text { Revista Brasileira de Economia } \\
\text { (Impresso) }\end{array}$ & 2 & $2,5 \%$ & $\begin{array}{l}\text { Revista de Gestão, Finanças e } \\
\text { Contabilidade }\end{array}$ & 1 & $1,3 \%$ \\
\hline $\begin{array}{l}\text { Revista Contemporânea de } \\
\text { Contabilidade (UFSC) }\end{array}$ & 1 & $1,3 \%$ & $\begin{array}{l}\text { Revista Eletrônica de Estratégia e } \\
\text { Negócios }\end{array}$ & 1 & $1,3 \%$ \\
\hline $\begin{array}{l}\text { Revista de Economia e Sociologia } \\
\text { Rural (Impresso) }\end{array}$ & 1 & $1,3 \%$ & Revista Gestão e Tecnologia & 2 & $2,5 \%$ \\
\hline Revista Universo Contábil & 3 & $3,9 \%$ & Contexto (UFRGS) & 1 & $1,3 \%$ \\
\hline Total & \multirow[t]{6}{*}{20} & \multirow[t]{6}{*}{$25,0 \%$} & Total & 14 & $17,5 \%$ \\
\hline & & & Revistas classificadas como B4 & Total & $\%$ \\
\hline & & & FACEF Pesquisa & 1 & $1,3 \%$ \\
\hline & & & $\begin{array}{l}\text { RCeC. Revista de Contabilidade e } \\
\text { Controladoria. }\end{array}$ & 1 & $1,3 \%$ \\
\hline & & & $\begin{array}{l}\text { Revista Evidenciação Contábil e } \\
\text { Finanças }\end{array}$ & 1 & $1,3 \%$ \\
\hline & & & Total & 3 & $3,9 \%$ \\
\hline
\end{tabular}

Nota: Fonte: Dados da pesquisa.

${ }^{a}$ Para as revistas: Revista de Contabilidade e Finanças, Revista de Administração Eletrônica, Revista de Administração Mackenzie e Revista de Administração Contemporânea foram agrupados os resultados das versões impressas e online, já que apresentavam a mesma classificação Webqualis.

\subsection{Tipificação metodológica}

Quanto à tipificação metodológica foram tabulados dados sobre a natureza do artigo, fundamentos teóricos utilizados, abordagem e recorte de pesquisa, métodos e amostragem. Oito artigos, $10 \%$, apresentam natureza teórica, ou seja, tinha como objetivo revisar a literatura, modelos, conceitos, propor nova teoria ou rever e ajustar as existentes. A maioria, $90 \%$ foram artigos teórico-empíricos, buscando, principalmente, descrever o comportamento e analisar os efeitos de variáveis sobre outras variáveis.

No que tange os fundamentos teóricos, além da estrutura clássica de capital, pressupostos de Modigliani e Miller, os conteúdos abordados no referencial teórico foram: a teoria do tradeoff e pecking order proposta por Myers (1984) e Myers e Majluf (1984), respectivamente, e teorias adicionais como: custos de transação, assimetria da informação, 
custo de agência, convergindo para o levantamento realizado por Harris e Raviv (1991), conceitos de governança corporativa e definições financeiras como: indicadores de liquidez, rentabilidade, eficiência e alavancagem, que se entrelaçam como as colocações de Myers e Majluf (1984), Myers (1984) e Rajan e Zingales (1995).

Dentre os trabalhos analisados $2,5 \%$ das pesquisas utilizaram estudo de caso, $10 \%$ realizaram um levantamento bibliográfico, porém não realizaram mapeamento similar, 1,25\% utilizaram survey e $86,25 \%$ tiveram como método a pesquisa documental. Especula-se então que a maior utilização da pesquisa documental se deve a utilização de banco de dados como Economática na qual disponibiliza informações completas sobre o balanço patrimonial das empresas listadas na bolsa. Estes bancos de dados contribuem para maior utilização de pesquisas quantitativas, e maior utilização de um recorte temporal misto, Tabela 4. Outros resultados indicam que as pesquisas tendem a utilizar uma amostragem não probabilística.

Tabela 4: Recorte temporal, abordagens e tipos de amostragens utilizadas nas pesquisas.

\begin{tabular}{lc|c|lc|c|lcc}
\hline Recorte temporal & Total & $\mathbf{\%}$ & Abordagem & Total & $\mathbf{\%}$ & Amostragem & Total & $\%$ \\
\hline Longitudinal & 5 & $6,25 \%$ & Mista & 1 & $1,25 \%$ & Probabilística & 1 & $1,25 \%$ \\
\hline Misto & 57 & $71,25 \%$ & Qualitativa & 8 & $10,00 \%$ & Não Probabilística & 71 & $88,75 \%$ \\
\hline Não se aplica & 8 & $10,00 \%$ & Quantitativa & 71 & $88,75 \%$ & Não utilizaram & 8 & $10,00 \%$ \\
\hline Transversal & 10 & $12,50 \%$ & & & & & & \\
\hline
\end{tabular}

Fonte: Dados da pesquisa.

Quanto ao ferramental estatístico, os autores têm utilizado as mais diversas para analisar os dados, entre as mais comuns: a regressão múltipla com dados em painel, utilizada por 51,06\% dos artigos pesquisados dentre eles os trabalhos de Futema, Basso e Kayo (2009), Silva e Valle (2008) e Terra (2007), além da análise da variância, utilizada por 2,13\% dos trabalhos, análise fatorial, 4,26\% (PEROBELLI; FAMÁ, 2003; SILVEIRA et al., 2008), análise de cluster, 3,19\%, e os modelos Rajan-Zingales e Frank-Goyal (MEDEIROS; DAHER, 2008), 2,13\%, foram os mais empregados.

A maior parte dos trabalhos estudados $(51,06 \%)$ empregaram análise de regressão múltipla com dados em painel. Tipicamente, este tipo de regressão é mais robusta em relação a séries temporais e cortes transversais, já que permite relacionar, no caso dos estudos analisados, diversas empresas ao longo do tempo, reduzindo a variabilidade, colinearidade, medindo melhor os efeitos individuais não observados isoladamente (WOOLDRIDGE, 2002).

Com isso, existem diferentes modelos usados para dados em painel, tendo como principal diferença os efeitos fixos ou aleatórios. Nos modelos de efeitos fixos, pressupõe que os regressores sejam correlacionados com o termo de erro, tornando os estimados de Mínimos Quadrados Ordinários (MQO) viesados e inconsistentes. Uma limitação deste modelo é a inclusão de variáveis que não oscilam com o tempo, gerando estimativas espúrias. Já para efeitos aleatórios, assume-se que o coeficiente angular é aleatório, ou seja, não correlacionados com os regressores.

Tipicamente para resolver problemas relacionados a heterocedasticidade e autocorrelação, é sugerido por Judge et al. (1985) e Davidson e Mackinnon (1993) que seja utilizado Mínimos Quadrados Generalizados Factíveis (Feasible Generalized Least Squares [FGLS]).

Se tratando de endogeneidade, os trabalhos pesquisados utilizaram metodologia mais robustas que MQO. Nakamura et al. (2007) utilizaram o Método dos Momentos Generalizados (Generalized Method of Moments - GMM) pois, ao incluir variáveis dummies para individualizar as empresas, se torna um instrumento eficiente para controlar a endogeneidade, ver maiores detalhes do emprego de GMM em Ozkan (2001). GMM também foi empregado por Rogers et al. (2013) na qual usaram a variável dependente defasada nos modelos testados, 
construindo assim, um painel dinâmico (ver descrição em Arellano e Bond (1991)), sendo mais rubousto para casos de endogeneidade.

Campos e Nakamura (2013) utilizaram, somente, defasagens de algumas variáveis no modelo para resolver tais problemas, porém usando MQO com efeitos fixos e aleatórios. Choi, Saito e Silva (2015) empregaram regressão em dois estágios (2MQO) com variáveis defasadas para minimizar problemas de endogeneidade. Loncan e Caldeira (2014) usaram equações estruturais para reduzir problemas de endogeneidade entre as variáveis.

No que tange a causalidade, Silveira, Perobelli e Barros (2008) usaram um conjunto de equações e estimaram por meio de Mínimos Quadrados de Três Estágios (MQ3E) ou 3SLS Three-Stages Least Squares, os coeficientes, pois, consideram que tal estratégia, gera uma estimação mais adequada para capturar padrões de causalidade reversa. O teste de causalidade mais difundido pode ser visto em Granger (1969) e um modelo robusto a este problema em Sims (1980).

\subsection{Variáveis utilizadas}

Os estudos selecionados envolvendo a estrutura de capital buscavam analisar não somente os fatores que influenciam a estrutura de capital das empresas, mas, também, o quanto a estrutura adotada pelas empresas influenciam as demais variáveis de interesse dos pesquisadores. As principais variáveis dependentes nos modelos de regressão podem ser observadas na Tabela 5 .

Tabela 5: Principais variáveis dependentes utilizadas nos estudos

\begin{tabular}{|c|c|c|c|}
\hline Variáveis utilizadas ${ }^{\mathrm{a}}$ & Total & $\%$ & Alguns trabalhos que utilizaram as variáveis dependentes \\
\hline Endividamento $^{\mathrm{b}}$ & 31 & $40,30 \%$ & $\begin{array}{l}\text { Bastos e Nakamura (2009), Brito, Corrar e Batistella (2007), Campos } \\
\text { e Nakamura (2015), Loncan e Caldeira (2014), Medeiros e Daher } \\
\text { (2008), Nakamura et al. (2007), Nicoli Junior e Funchal (2013), } \\
\text { Pohlmann e Iudícibus (2010), Silva e Valle (2008), Teixeira, Nossa e } \\
\text { Funchal (2011) e Terra (2007). }\end{array}$ \\
\hline $\begin{array}{l}\text { Alavancagem } \\
\text { (Financeira ou } \\
\text { contábil) }\end{array}$ & 9 & $11,70 \%$ & $\begin{array}{l}\text { Choi, Saito e Silva (2015), Martins e Terra (2014), Silveira, Perobelli } \\
\text { e Barros (2008) e Wilson e Valle (2015). }\end{array}$ \\
\hline
\end{tabular}

Fonte: Dados da pesquisa.

Nota: ${ }^{\mathrm{a} F o r a m}$ mantidas as mesmas notações dos autores. ${ }^{\mathrm{b}} \mathrm{A}$ variável endividamento foi agregada, porém, dependendo do trabalho utilizado pode apresentar as seguintes divisões: curto prazo, longo prazo, total, contábil, de mercado, bruto, oneroso, defasado, variação do endividamento, endividamento alvo.

No que tange a variável endividamento as descrições de suas métricas de cálculo podem ser observadas no Quadro 1. A principal variável dependente da estrutura de capital é o endividamento. Tais métricas mostram alternativas de alavancagem, buscando abordar diferentes considerações sobre o endividamento: longo prazo versus total, valor de mercado versus contábil, bem como métricas alternativas com a utilização de logaritmo das grandezas patrimoniais. Tal processo permite, então, entender a dinâmica entre a escolha ótima de capital de terceiros e próprio, e relacionar o endividamento da empresa às suas características, abrangendo, por exemplo, o setor ou aspectos macroeconômicos (PÓVOA; NAKAMURA, 2015).

Outro ponto a ser considerado na construção de tal indicador seria a homogeneidade como é tratado o capital de terceiros, ignorando as diversas fontes de captação (dívida com bancos, títulos corporativos, empréstimos com coligadas, arrendamentos mercantis, governo, fornecedores, entre outros), sendo estes distintos entre si, tais como: origem, maturidade, colateralidade, acessibilidade, prioridade de recebimento e impacto sobre o fluxo de caixa, 
custos de transação, incentivos aos gerentes, benefícios, dentre outros, ver maiores detalhes em Póvoa e Nakamura $(2014,2015)$, podendo tais tratamentos serem observadas em variáveis agregadas, como mostrado no Quadro 1.

Quadro 1: Algumas das diversas métricas de cálculo da variável endividamento

\begin{tabular}{|l|l|}
\hline \multicolumn{1}{|c|}{ Autores } & \multicolumn{1}{c|}{ Fórmula } \\
\hline $\begin{array}{l}\text { Bastos e Nakamura (2009), Brito, Corrar e Batistella (2007), } \\
\text { Campos e Nakamura (2015), Medeiros e Daher (2008), Nakamura } \\
\text { et al. (2007), Silva e Valle (2008), Terra (2007) }\end{array}$ & \\
\hline $\begin{array}{l}\text { Bastos e Nakamura (2009), Campos e Nakamura (2015), } \\
\text { Nakamura et al. (2007). }\end{array}$ & (PC + ELP) / ATM \\
\hline Bastos e Nakamura (2009), Brito, Corrar e Batistella (2007) & PC / AT \\
\hline Bastos e Nakamura (2009), Brito, Corrar e Batistella (2007) & ELP/AT \\
\hline Bastos e Nakamura (2009) & DFCP/ ATM \\
\hline Bastos e Nakamura (2009) & DFLP / ATM \\
\hline Brito, Corrar e Batistella (2007), Terra (2007) & (PC + ELP) / PL \\
\hline Loncan e Caldeira (2014) & VCD / (VCD + VCP) \\
\hline Nicoli Junior e Funchal (2013), Teixeira, Nossa e Funchal (2011) & LN(PC+ELP) \\
\hline Pohlmann e Iudícibus (2010) & (PC + PC) / AT ajustado pela inflação \\
\hline Pohlmann e Iudícibus (2010) & PC / AT ajustado pela inflação \\
\hline Pohlmann e Iudícibus (2010) & ELP / AT ajustado pela inflação \\
\hline Silva e Valle (2008) & ELP/(PC+ELP) \\
\hline Teixeira, Nossa e Funchal (2011) & LN((PC+ELP)/AT) \\
\hline Teixeira, Nossa e Funchal (2011) & LN((PC+ELP)/PL) \\
\hline Teixeira, Nossa e Funchal (2011) & LN(ELP/AT) \\
\hline Teixeira, Nossa e Funchal (2011) & LN(PC/AT) \\
\hline Terra (2007) & ELP/PL \\
\hline Terra (2007) & VCD/VM \\
\hline
\end{tabular}

Fonte: Dados da pesquisa;

Nota: Em que: $\mathrm{PC}=$ Passivo Circulante. $\mathrm{ELP}=$ Exigível a Longo Prazo. AT $=$ Ativo Total. ATM $=$ Ativo Total a Valor de Mercado. $\mathrm{PL}=$ Patrimônio Líquido. $\mathrm{LN}=$ Logaritmo Natural. DFCP $=$ Debêntures e Financiamentos de Curto Prazo, DFLP = Debêntures e Financiamentos de Longo Prazo. VCD = Valor Contábil da Dívida. VCP = Valor Contábil do Patrimônio. VM = Valor de Mercado.

Já nos estudos em que tinha a estrutura de capital como variável independente, as principais variáveis explanadas foram: Rentabilidade, Crescimento, Maturidade da dívida, Benefícios fiscais, Beta de mercado, Binária - emissões públicas ou privadas, Distribuição dos lucros, Emissão de ações, Especificidade dos ativos, Estrutura dos ativos, Inadimplência, Índice de governança, Índice de internacionalização, Investimentos, Liquidez, Lucros, Período frio, Período quente, Remuneração média, Retorno da ação, Variação na emissão de ações.

Quanto as variáveis independentes, as mais utilizadas para explicar a estrutura de capital, representando 51,42\% das variáveis usadas, podem ser observadas na Tabela 6 . Apesar desta vasta quantidade de variáveis poucos trabalhos abordaram a questão da endogeneidade. Martins e Terra (2014), Campos e Nakamura (2013) abordaram rasamente o conceito de endogeneidade defasando uma variável em um de seus modelos. Nakamura et al. (2007) usaram o Método de Momentos Generalizados, afirmando que seria mais robusto para tal problema. Modelos robustos a endogeneidade também foram gerados por Portal, Zani e Silva (2012) e Choi, Saito e Silva (2015). Futema, Basso e Kayo (2009) informaram que existe tal problema, porém por se tratar de uma replicação fugiria do escopo da pesquisa. Porém em nenhum dos trabalhos pesquisados este problema foi abordo como omissão de variáveis. 
Tabela 6: Principais variáveis independentes utilizadas

\begin{tabular}{|c|c|c|c|}
\hline Variáveis $^{\mathbf{a}}$ & Total & $\%$ & Alguns dos trabalhos que as utilizaram \\
\hline Tamanho & 29 & $10,28 \%$ & $\begin{array}{l}\text { Perobelli e Famá (2003), Brito, Corrar e Batistella (2007), Terra (2007), } \\
\text { Nakamura et al. (2007), Silveira, Perobelli e Barros (2008), Silva e Valle } \\
\text { (2008), Bastos e Nakamura (2009), Pohlmann e Iudícibus (2010), Teixeira, } \\
\text { Nossa e Funchal (2011), Nicoli Junior e Funchal (2013), Loncan e } \\
\text { Caldeira (2014), Martins e Terra (2014), Wilson e Valle (2015) e Campos } \\
\text { e Nakamura (2015). }\end{array}$ \\
\hline Rentabilidade & 23 & $8,16 \%$ & $\begin{array}{l}\text { Brito, Corrar e Batistella (2007), Nakamura et al. (2007), Terra (2007), } \\
\text { Silva e Valle (2008), Silveira, Perobelli e Barros (2008), Bastos e } \\
\text { Nakamura (2009), Teixeira, Nossa e Funchal (2011), Loncan e Caldeira } \\
\text { (2014) e Wilson e Valle (2015). }\end{array}$ \\
\hline Tangibilidade & 23 & $8,16 \%$ & $\begin{array}{l}\text { Terra (2007), Medeiros e Daher (2008), Silva e Valle (2008), Silveira, } \\
\text { Perobelli e Barros (2008), Bastos e Nakamura (2009), Teixeira, Nossa e } \\
\text { Funchal (2011), Nicoli Junior e Funchal (2013), Martins e Terra (2014), } \\
\text { Campos e Nakamura (2015) e Wilson e Valle (2015). }\end{array}$ \\
\hline Crescimento & 15 & $5,32 \%$ & $\begin{array}{l}\text { Brito, Corrar e Batistella (2007), Nakamura et al. (2007), Silva e Valle } \\
\text { (2008), Silveira, Perobelli e Barros (2008), Bastos e Nakamura (2009), } \\
\text { Pohlmann e Iudícibus (2010), Nicoli Junior e Funchal (2013), Martins e } \\
\text { Terra (2014), Campos e Nakamura (2015) e Wilson e Valle (2015). }\end{array}$ \\
\hline Risco & 14 & $4,96 \%$ & $\begin{array}{l}\text { Brito, Corrar e Batistella (2007), Nakamura et al. (2007), Terra (2007), } \\
\text { Bastos e Nakamura (2009), Pohlmann e Iudícibus (2010), Nicoli Junior e } \\
\text { Funchal (2013) e Wilson e Valle (2015). }\end{array}$ \\
\hline Lucratividade & 11 & $3,90 \%$ & $\begin{array}{l}\text { Medeiros e Daher (2008), Pohlmann e Iudícibus (2010), Martins e Terra } \\
\text { (2014) e Campos e Nakamura (2015). }\end{array}$ \\
\hline Setor & 11 & $3,90 \%$ & $\begin{array}{l}\text { Terra (2007), Silva e Valle (2008), Bastos e Nakamura (2009), Pohlmann e } \\
\text { Iudícibus (2010) e Choi, Saito e Silva (2015). }\end{array}$ \\
\hline Liquidez & 10 & $3,55 \%$ & $\begin{array}{l}\text { Nakamura et al. (2007), Bastos e Nakamura (2009), Teixeira, Nossa e } \\
\text { Funchal (2011), Loncan e Caldeira (2014) e Martins e Terra (2014). }\end{array}$ \\
\hline $\begin{array}{l}\text { Valor de } \\
\text { mercado }\end{array}$ & 9 & $3,19 \%$ & $\begin{array}{l}\text { Medeiros e Daher (2008), Bastos e Nakamura (2009), Futema; Basso; } \\
\text { Kayo (2009), Teixeira, Nossa e Funchal (2011), Loncan e Caldeira (2014) } \\
\text { e Choi, Saito e Silva (2015) }\end{array}$ \\
\hline
\end{tabular}

Fonte: Dados da pesquisa.

Nota: ${ }^{a}$ Foram mantidas as mesmas notações dos autores.

A literatura analisada utiliza as variáveis apontadas como relevante para influenciar a estrutura de capital, como proposto por Myers (1984), Myers e Majluf (1984) e Rajan e Zingales (1995). Contudo, a diversidade de variáveis é relevante. Assim, propõe neste artigo uma classificação de acordo com algumas categorias, como pode ser observado no Quadro 2.

Quadro 2: Categorias e variáveis

\begin{tabular}{|l|l|}
\hline \multicolumn{1}{|c|}{ Categorias } & \multicolumn{1}{c|}{ Variáveis } \\
\hline Liquidez & Liquidez da empresa (geral, seca, imediata, corrente) \\
\hline Tamanho & $\begin{array}{l}\text { Volume de ativos, volume de vendas, despesas de vendas, volume do ativo permanente, } \\
\text { concentração do setor, economia fiscal e impostos (capacidade de gestão tributária da } \\
\text { empresa dentro das especificidades de casa segmento). }\end{array}$ \\
\hline Macroeconômica & PIB, inflação, taxa de juros, câmbio, ciclo de vida do setor, crise, \\
\hline Rentabilidade & ROA, ROE, ROI, retorno das ações, EBTIDA, volume pagos em dividendos \\
\hline Risco & $\begin{array}{l}\text { Tempo de abertura do negócio, tipo de capital, tangibilidade dos ativos, assimetria de } \\
\text { informação e transparência da empresa com a emissão de American Depositary Receipts } \\
\text { (ADR). }\end{array}$ \\
\hline $\begin{array}{l}\text { Estruturo } \\
\text { capital }\end{array}$ & Escolaridade, gênero, idade, reputação da faculdade de formação. \\
\hline
\end{tabular}

Fonte: Dados da pesquisa. 
A primeira categoria seria a liquidez dos ativos, na qual englobaria aspectos internos como a liquidez da empresa (geral, seca, imediata, corrente). Este indicador pode ser a relação entre o ativo, exceto o intangível, dividido pelo ativo total, ou um fator envolvendo tais variáveis.

A segunda categoria refere-se a variáveis como tamanho, na qual faz maior sentido se comprado com seus pares. Neste contexto tem-se a concentração do setor, economia fiscal e impostos (capacidade de gestão tributária da empresa dentro das especificidades de cada segmento), variam de acordo com o setor/segmento da empresa. Cabe destacar que se seguida a proposta de Myers (1984), segmentar por setor, todas as empresas de tal setor teriam, teoricamente, as mesmas condições exceto tamanho, que refletiria o crescimento da empresa comparado a seus pares.

A terceira dimensão seria a macroeconômica, na qual propõe a criação de um fator envolvendo variáveis como: PIB, Selic, Inflação, renda per-capta e Dólar. Já que variáveis macroeconômicas influenciam as maneiras de financiamento, principalmente no que diz respeito ao longo prazo (KUNT; MAKSIMOVIC, 1999). Os autores mostram ainda a estreita ligação entre dívidas de longo prazo e subsídios governamentais.

Para a dimensão rentabilidade, quarta dimensão, propõe um fator envolvendo variáveis que medem de alguma maneira a rentabilidade da empresa, tais como: ROA, ROE, ROI, retorno das ações, EBTIDA, volume pagos em dividendos.

A quinta dimensão, risco, englobaria os riscos da empresa. Admite-se, também, aspectos relacionados a assimetria de informação, na qual sugere a criação de uma variável de mercado, refletida, por exemplo, pelo beta de mercado. Outra possível variável seria alguma métrica de transparência da empresa como emissão de ADR que possivelmente captaria os custos de agência envolvidos e refletidos nos preços das ações. Já que aspectos relacionados a custos de agência e assimetria de informação são elementos determinantes da estrutura de capital (JENSEN; MECKLING, 1976). Na sexta dimensão, aspectos relacionados ao gestor que variam de acordo com sua experiência de mercado, sua aversão ao risco, gênero, idade, escolaridade e reputação da faculdade.

Por fim, na sétima dimensão seria relevante incluir a variável alavancagem defasada no modelo, já que a próxima estrutura de capital baseia-se na passada para suas modificações (OZKAN, 2001, DANG; KIM; SHIN, 2012).

\subsection{Alguns dos principais resultados dos trabalhos pesquisados}

Bastos e Nakamura (2009), Medeiros e Daher (2008) e Perobelli e Famá (2003) mostraram que para o cenário nacional a POT foi a corrente dominante na determinação da estrutura de capital das empresas pesquisadas. Usando dados em painel, Bastos e Nakamura (2009) mostraram que as variáveis Liquidez, Rentabilidade, Valor de mercado, Tamanho e Risco são condizentes com a teoria da POT. Os autores encontraram ainda que a variável crescimento suporta os constructos da STT. Medeiros e Daher (2008) encontraram evidências relevantes, como metodologia similar, que as variáveis: Tangibilidade, Vendas, Dividendos e Déficit financeiro são relevantes para explicar também a POT. Outras variáveis também mostraram resultados significativos no trabalho de Albanez e Valle (2009), como por exemplo: o nível de governança das empresas e a emissão de ADR, configurando a assimetria de informação envolvendo as empresas.

A estrutura de capital das empresas brasileiras analisadas foi estabelecida como resultado de uma hierarquia de financiamento, cuja prioridade máxima são recursos gerados internamente, seguidos pelo endividamento e, por último, pela emissão de ações. Foi destacado ainda por Medeiros e Daher (2005) que ao colocar na balança, de um lado as dificuldades de 
obtenção de crédito no país, e do outro, as dificuldades de captação de recursos via mercado de ações, a preferência das empresas recai sobre o endividamento, prevalecendo a POT.

Bastos e Nakamura (2009) mostraram ainda que as variáveis: rentabilidade, valor de mercado e tamanho foram as mais significantes, convergindo com o trabalho de Rajan e Zingales (1995). Os autores mostraram ainda que a assimetria de informação é relevante para explicar a estrutura de capital das empresas. Ainda no contexto da assimetria de informação Albanez e Valle (2009) identificaram que empresas com menor assimetria de informação são menos endividadas, podendo ter mais acesso ao mercado em que exista maior sensibilidade, mercado de longo prazo.

Santos, Pimenta Júnior e Cicconi (2009), por meio de um survey, mostraram que os custos de transação são relevantes para explicar a estrutura de capital das empresas analisadas, corroborando as colocações de Myers (1984). Estes resultados mostraram que a peking order foi a teoria de estrutura de capital predominante dentre as empresas pesquisadas.

Martins e Terra (2014) encontraram que as duas teorias são suportadas pelas empresas pesquisadas. As variáveis tangibilidade e tamanho foram representativas para explicar a STT e liquidez e lucratividade, ambas negativamente relacionadas, suportam a POT, similar ao explanado por Brealey, Myers e Allen (2011). Nakamura et al. (2007) também encontraram resultados que suportam as duas teorias, indicando que as empresas brasileiras pesquisadas seguem uma hierarquia de financiamento (peking order) ao mesmo tempo de uma dinâmica de ajuste a um grau de endividamento ótimo de curto prazo (tradeoff).

Por outro lado, Eid Júnior (1996), apontou que a seleção da estrutura de capital varia de acordo com a oportunidade de mercado, quando os recursos não necessários e mais baratos, descartando, pelo menos em primeiro plano, as teorias convencionais, POT e a STT. Contudo, o autor adverte que existe, em segundo plano, uma hierarquia de financiamento conforme prevista pela POT. Neste contexto, as empresas tenderiam a optar por financiamento de acordo com a oportunidade de mercado, colocações similares a proposta de market-timing (BREALEY; MYERS; ALLEN, 2011), ordem de captação e modelos de relação estática.

Não muito distante de alguns dos resultados brasileiros, países como México e Chile mostram que a pecking order foi mais robusta para explicar a estrutura de capital das empresas (BASTOS; NAKAMURA, 2009). Outras colocações relevantes foram realizadas por Silva e Valle (2008) e Leal (2008). Silva e Valle (2008) compararam empresas brasileiras e americanas e identificaram que empresas americanas possuem nível médio de endividamento de longo prazo superior as brasileiras. Foi apontado ainda, que o maior endividamento de curto prazo é uma tendência de países em desenvolvimento. Indicações semelhantes foram colocadas por Leal (2008) apontando que em países onde a economia é mais estável as empresas tendem a contrair mais dívida de longo prazo, utilizando, principalmente o mercado de capitais ou outras fontes no mercado bancário.

\section{Considerações Finais}

Esta pesquisa buscou realizar um levantamento da temática estrutura de capital nos periódicos nacionais. Para tal, foi utilizada a base de periódicos Capes com as palavras-chave estrutura de capital e estrutura da dívida. Foram selecionados artigos revisados por pares que apresentaram um destes termos no título ou nas palavras-chave. Com isso foram selecionados 80 artigos classificados no webqualis A2, B1 a B4.

Os resultados mostram que a literatura a respeito da estrutura de capital está se desenvolvendo, ao evidenciarem que existem mais variáveis significativas do que apontadas nos trabalhos de Brealey, Myers e Allen (2011), Myers e Majluf (1984), Myers (1984) e Rajan e Zingales, (1995). Cabe destacar ainda, a utilização de metodologias mais robustas, buscando 
resolver problemas de endogeneidade (Método dos Momentos Generalizados, Painel dinâmico, regressão em dois e três estágios e equações estruturais) e causalidade (regressão em três estágios). Contudo, a diversidade metodológica e a utilização de uma gama de variáveis dificultariam uma compreensão do fenômeno estudado, já que a representatividade estatística de tais variáveis varia de estudo para estudo e de método para método.

Outras variáveis macroeconômicas foram também importantes, porém utilizadas em menor expressão pelos autores, tais como: PIB, Selic, Inflação, concentração, câmbio, dentre outras, além de variáveis relacionadas ao gestor, como: gênero, idade, escolaridade, dentre outras.

Pontos críticos ainda podem ser observados na construção da principal variável dependente nos modelos de regressão utilizados: o endividamento. Os trabalhos pesquisados, em sua grande maioria, utilizam tal variável, de maneira agregada ignorando a diversidade de sua composição (maturidade, origem, acessibilidade, prioridade de recebimento, dentre outros) bem como seus reflexos sobre o fluxo de caixa e demais contas patrimoniais (PÓVOA; NAKAMURA, 2014, 2015).

No que tange à aplicação das teorias de estrutura de capital, POT e STT, os resultados são divergentes. Pesquisadores como Bastos e Nakamura (2009), Medeiros e Daher (2008) e Perobelli e Famá (2003) apontam para a utilização da POT enquanto os trabalhos de Martins e Terra (2014) e Nakamura et al. (2007) suportam as duas teorias. Nakamura et al. (2007) apontam ainda que as duas teorias não são concorrentes, mas, sim complementares ao passo que as empresas têm uma hierarquia de preferência por endividamento e buscam ajustar a sua estrutura a uma base ótima. Contudo, as empresas estão condicionadas a oportunidade de mercado, para depois adotaram uma hierarquia (EID JÚNIOR, 1996). Com estes indícios abre espaço para analisar o quanto políticas de fomento governamental influência a opção pela dívida (subsídios governamentais para a indústria possui estreita ligação com as dívidas de longo prazo (KUNT; MAKSIMOVIC, 1999)), já que, normalmente, tais políticas possuem melhor acesso que outras fontes de crédito, e em caso de resultado significativo poderia inviabilizar as teorias POT e STT.

Foram propostas ainda sete dimensões com a construção de alguns fatores que aglomerassem as diversas variáveis estudadas, tais como: a dimensão liquidez dos ativos, dimensão tamanho, dimensão macroeconômica, dimensão rentabilidade, dimensão gestão, a dimensão risco empresarial e a própria alavancagem defasada.

Quanto à estrutura de capital, sugere para pesquisas futuras que os artigos busquem analisar a estrutura de capital das empresas nacionais separando por setores, já que existem suas particularidades (MYERS, 1984). Comparações com outros países em desenvolvimento e desenvolvidos poderão ser benéficas para a literatura, já que poucos dos trabalhos analisados utilizavam tal segmentação. No tocante, tais teorias foram desenvolvidas no contexto norte americano (MEDEIROS; DAHER, 2008), prevalecendo à estabilidade econômica e mercado de capitais desenvolvido.

Esta pesquisa possui algumas limitações quanto a utilização dos termos empregados, já que pode haver mais trabalhos publicados que abordam a temática estrutura de capital, porém não foram captados com os filtros utilizados. É importante frisar que muitas das vezes os autores utilizam termos chamativos no título e nas palavras-chave, que muitas das vezes, não refletem a essência do trabalho (SERRA; FERREIRA, 2014). Sugere aqui para pesquisas futuras realizar um levantamento internacional de tal temática, ou expandir os termos utilizados. 


\section{Referências}

AKERLOF, G. A. The market for "Lemons": quality uncertainty and the market mechanism. The Quarterly Journal of Economics, v. 84, n. 3, p. 488-500, 1970. Disponível em: $<$ http://www.jstor.org/stable/1879431>

ALBANEZ, T.; VALLE, M. R. DO. Impactos da assimetria de informação na estrutura de capital de empresas brasileiras abertas. São Paulo. Revista Contabilidade e Finanças, v. 20, n. 51, /dez., p. 6-27, 2009. http://dx.doi.org/10.1590/S1519-70772009000300002

APPOLINÁRIO, F. Metodologia da ciência: filosofia e prática da pesquisa. São Paulo: Cegage Learning, 2009.

ARELLANO, M.; BOND, S. Employment equations some tests of specification for panel data: Monte Carlo evidence and an application to employment equations. The Review of Economic Studies, v. 58, n. 2, p. 277-297, 1991. https://doi.org/10.2307/2297968

BAE, K.; KANG, J.; WANG, J. Employee treatment and firm leverage: A test of the stakeholder theory of capital structure. Journal of Financial Economics, v. 100, n. 1, p. 130 153, 2011. http://dx.doi.org/10.1016/j.jfineco.2010.10.019

BASTOS, D. D.; NAKAMURA, W. T. Determinantes da estrutura de capital das companhias abertas no Brasil, México e Chile no período 2001-2006. São Paulo. Revista Contabilidade \& Finanças, v. 20, n. 50, /ago., p. 75-94, 2009. http://dx.doi.org/10.1590/S151970772009000200006

BREALEY, R. A.; MYERS, S. C.; ALLEN, F. Principles of corporate finance. $10^{\circ} \mathrm{ed}$. New York: McGraw-Hill Education, 2011.

BRITO, G. A. S.; CORRAR, L. J.; BATISTELLA, F. D. Fatores determinantes da estrutura de capital das maiores empresas que atuam no Brasil. São Paulo. Revista de Contabilidade e Finanças, v. 18, n. 43, /abr., p. 9-19, 2007. http://dx.doi.org/10.1590/S151970772007000100002

CAMPOS, A. L. S.; NAKAMURA, W. T. Rebalanceamento da estrutura de capital: endividamento setorial e folga financeira. Rio de Janeiro. Revista de Administração Contemporânea, v. 19, n. Edição Especial, p. 20-37, 2015. http://dx.doi.org/10.1590/19827849rac20151789

CAPES, C. DE A. DE P. DE N. S. Portal de Periódicos Capes, 2017. Disponível em: $<$ http://www-periodicos-capes-gov-br $>$ Disponível em: $<$ http://www-periodicos-capes-gov-br $>$

CHOI, D. Y.; SAITO, R.; SILVA, V. A. B. Estrutura de capital e remuneração dos funcionários: evidência empírica no Brasil. Rio de Janeiro. Revista de Administração Contemporânea, v. 19, n. 2, /abr., p. 249-269, 2015. http://dx.doi.org/10.1590/1982-7849rac20151600

DANG, V. A.; KIM, M.; SHIN, Y. Asymmetric capital structure adjustments: New evidence from dynamic panel threshold models. Journal of Empirical Finance, v. 19, n. 4, p. 465-482, 2012. http://dx.doi.org/10.1016/j.jempfin.2012.04.004

DAVIDSON, R.; MACKINNON, J. G. Estimation and inference in econometrics. New York: Oxford University Press, 1993.

EID JÚNIOR, W. Custo e estrutura de capital: o comportamento das empresas brasileiras. São Paulo. Resvista de Administração de Empresas, v. 36, n. 4, /dez., p. 51-59, 1996. 
http://dx.doi.org/10.1590/S0034-75901996000400006

FRANK, M. Z.; GOYAL, V. K. Testing the pecking order theory of capital structure. Journal of Financial Economics, v. 67, p. 217-248, 2003. https://doi.org/10.1016/S0304$405 \mathrm{X}(02) 00252-0$

FUTEMA, M. S.; BASSO, L. F. C.; KAYO, E. K. Estrutura de capital, dividendos e juros sobre o capital próprio: testes no Brasil. São Paulo. Revista Contabilidade \& Finanças, v. 20, n. 49, p. 44-62, 2009. http://dx.doi.org/10.1590/S1519-70772009000100004

GIL, A. C. Métodos e técnicas de pesquisa social. $6^{\circ}$ ed. São Paulo: Atlas, 2008.

GRANGER, C. W. J. Investigating Causal Relations by Econometric Models and Crossspectral Methods. Econometrica, v. 37, n. 3, p. 424-438, 1969. http://dx.doi.org/10.2307/1912791

HARRIS, M.; RAVIV, A. The theory of capital structure. The Journal of Finance, v. 46, n. 1, , p. 297-355, 1991. http://dx.doi.org/10.2307/2328697

JENSEN, M. C.; MECKLING, W. H. Theory of the firm: managerial behavior, agency costs and ownership structure. Journal of Financial Economics, v. 3, n. 4, 1976. http://dx.doi.org/10.1016 / 0304-405X (76) 90026-X

JUDGE, G. G. et al. The theory and practice of econometrics. 2. ed. New York: Wiley, 1985.

KUNT, A. D.; MAKSIMOVIC, V. Institutions, financial markets, and firm debt maturity. Journal of Financial Economics, v. 54, p. 295-336, 1999. https://doi.org/10.1016/S0304405X(99)00039-2

LEAL, R. P. C. Estrutura de capitais comparada: Brasil e mercados emergentes. São Paulo. Revista de Administração de Empresas, v. 48, n. 4, /dez., p. 67-78, 2008. http://dx.doi.org/10.1590/S0034-75902008000400007

LONCAN, T. R.; CALDEIRA, J. F. Estrutura de capital, liquidez de caixa e valor da empresa: estudo de empresas brasileiras cotadas em bolsa. São Paulo. Revista de Contabilidade e Finanças, v. 25, n. 64, /abr., p. 46-59, 2014. http://dx.doi.org/10.1590/S151970772014000100005

MACHADO, J. H.; GODOY, C. R. Fatores determinantes da estrutura de capital nas companhias integradas de petróleo. Curitiba. Revista de Contabilidade e Controladoria, v. 5, n. 1, /abr., p. 82-98, 2013. http://dx.doi.org/10.5380/rcc.v5i1.29787

MACHADO, M. A. V.; MEDEIROS, O. R. DE; EID JÚNIOR, W. Problems in measuring capital structure: empiric evidence in Brazil. Vitória. Brazilian Business Review, v. 7, n. 1, /apr., p. 23-41, 2010. http://dx.doi.org/10.15728/bbr.2010.7.1.2

MARTINS, H. C.; TERRA, P. R. S. Determinantes nacionais e setoriais da estrutura de capital na América Latina. Rio de Janeiro. Revista de Administração Contemporânea, v. 18, n. 5, /out., p. 577-597, 2014. http://dx.doi.org/10.1590/1982-7849rac20141154

MATOS, J. A. DE. Theorical foundations of corporate finance. [s.1.] Princeton, 2001.

MEDEIROS, O. R.; DAHER, C. E. Testando a teoria de hierarquização de fontes de financiamento nas empresas brasileiras. São Paulo. Revista de Contabilidade e Finanças, v. 16, n. 37, /abr., p. 37-45, 2005. http://dx.doi.org/10.1590/S1519-70772005000100003

MEDEIROS, O. R.; DAHER, C. E. Testando teorias alternativas sobre a estrutura de capital 
nas empresas brasileiras. Curitiba. Revista de Administração Contemporânea, v. 12, n. 1, /mar., p. 177-199, 2008. http://dx.doi.org/10.1590/S1415-65552008000100009

MODIGLIANI, F.; MILLER, M. H. The cost of capital, corporation finance and the theory of investment. The American Economic Review, v. 48, n. 3, , 1958. Disponível em: $<$ http://www.jstor.org/stable/1809766>

MODIGLIANI, F.; MILLER, M. H. Corporate Income taxes and the cost of capital: a correction. The American Economic Review, v. 53, n. 3, , p. 433-443, 1963. Disponível em: $<$ http://www.jstor.org/stable/1809167>

MYERS, S. C. Determinants of corporate borrowing. Journal of Financial Economics, v. 5, n. 2, p. 147-175, 1977. https://doi.org/10.1016/0304-405X(77)90015-0

MYERS, S. C. The capital structure puzzle. The Journal of Finance, v. 39, n. 3, 1984. Disponível em: <http://www.jstor.org/stable/2327916>

MYERS, S. C.; MAJLUF, N. S. Corporate financing and investment decisions when firms have information that investors do not have. Journal of Financial Economics, v. 13, p. 187-221, 1984. https://doi.org/10.1016/0304-405X(84)90023-0

NAKAMURA, W. T. et al. Determinantes de estrutura de capital no mercado brasileiro: análise de regressão com painel de dados no período 1999-2003. São Paulo. Revista Contabilidade \& Finanças, v. 44, n. mai./ago., p. 72-85, 2007. http://dx.doi.org/10.1590/S151970772007000200007

NICOLI JUNIOR, J.; FUNCHAL, B. O efeito da diversificação corporativa na estrutura de capital das firmas brasileiras. São Paulo. Revista Contabilidade \& Finanças, v. 24, n. 62, /ago., p. 154-161, 2013. http://dx.doi.org/10.1590/S1519-70772013000200006

OZKAN, A. Determinants of capital structure and adjustment to long run target: Evidence from UK company panel data. Journal of Business Finance and Accounting, v. 28, n. 1-2, p. 175198, 2001. http://dx.doi.org/10.1111/1468-5957.00370

PEROBELLI, F. F. C.; FAMÁ, R. Fatores determinantes da estrutura de capital para empresas latino-americanas. Curitiba. Revista de Administração Contemporânea, v. 7, n. 1, /mar., p. 9-35, 2003. http://dx.doi.org/10.1590/S1415-65552003000100002

POHLMANN, M. C. et al. Impacto da especificidade de ativos nos custos de transação, na estrutura de capital e no valor da empresa. São Paulo. Revista Contabilidade \& Finanças, v. 15, n. Edição Especial, , p. 24-40, 2004. http://dx.doi.org/10.1590/S1519-70772004000400002

POHLMANN, M. C.; IUDÍCIBUS, S. DE. Relação entre a tributação do lucro e a estrutura de capital das grandes empresas no Brasil. São Paulo. Revista Contabilidade \& Finanças, v. 21, n. 53, /ago., p. 1-25, 2010. http://dx.doi.org/10.1590/S1519-70772010000200002

PORTAL, M. T.; ZANI, J.; SILVA, C. E. S. Fricções financeiras e a substituição entre fundos internos e externos em companhias brasileiras de capital aberto. São Paulo. Revista de Contabilidade \& Finanças, v. 23, n. 58, /abr., p. 19-32, 2012.

PÓVOA, A. C. S.; NAKAMURA, W. T. Homogeneidade versus heterogeneidade da estrutura de dívida: um estudo com dados em painel. São Paulo. Revista Contabilidade \& Finanças, v. 25, n. 64, /abr., p. 19-32, 2014.

PÓVOA, A. C. S.; NAKAMURA, W. T. Relevância da estrutura de dívida para os determinantes da estrutura de capital: um estudo com dados em painel. Revista 
Contemporânea de Contabilidade, v. 12, n. 25, /abr., p. 03-26, 2015. Disponível em: $<$ https://periodicos.ufsc.br/index.php/contabilidade/article/view/2175-

8069.2015v12n25p03>http://dx.doi.org/10.5007/2175-8069.2015v12n25p27

RAJAN, R. G.; ZINGALES, L. What do we know about capital structure? some evidence from international. The Journal of Finance, v. 50, n. 5, p. 1421-1460, 1995. http://dx.doi.org/10.2307 / 2329322

ROGERS, D. et al. Rating de crédito e estrutura de capital: evidências da América Latina. Rio de Janeiro. Revista Brasileira de Finanças, v. 11, n. 3, , p. 311-341, 2013.

SANTOS, C. M.; PIMENTA JÚNIOR, T.; CICCONI, E. G. Determinantes da escolha da estrutura de capital das empresas brasileiras de capital aberto: um survey. São Paulo. Revista de Administração, v. 44, n. 1, /mar., p. 70-81, 2009.

SERRA, F. A. R.; FERREIRA, M. A. P. V. Comentário editorial: o título, resumo e palavraschave dos artigos. São Paulo. Revista Ibero-Americana de Estratégia, v. 13, n. 4, /dez., 2014. http://dx.doi.org/10.5585/riae.v13i4.2179

SILVA, A. D. F.; VALLE, M. R. DO. Análise da estrutura de endividamento: um estudo comparativo entre empresas brasileiras e americanas. Curitiba. Revista de Administração Contemporânea, v. 12, n. 1, p. 201-229, 2008. http://dx.doi.org/10.1590/S141565552008000100010

SILVEIRA, A. D. M. DA; PEROBELli, F. F. C.; BARROS, L. A. B. DE C. Governança corporativa e os determinantes da estrutura de capital: evidências empíricas no Brasil. Curitiba. Revista de Administração Contemporânea, v. 12, n. 3, /set., p. 763-788, 2008. http://dx.doi.org/10.1590/S1415-65552008000300008

SIMS, C. A. The Econometric Society. Econometrica, v. 48, n. 1, p. 1-48, 1980. http://dx.doi.org/10.2307/1912017

TEIXEIRA, E. A.; NOSSA, V.; FUNCHAL, B. O índice de sustentabilidade empresarial (ISE) e os impactos no endividamento e na percepção de risco. São Paulo. Revista Contabilidade \& Finanças, v. 22, n. 55, /abr., p. 29-44, 2011. http://dx.doi.org/10.1590/S151970772011000100003

TERRA, P. R. S. Estrutura de capital e fatores macroeconômicos na América Latina. São Paulo. Revista de Administração, v. 42, n. 2, p. 192-204, 2007.

VICKERS, D. The cost of capital and the structure of the firm. Journal of Finance, v. 25, n. 1, 1970. http://dx.doi.org/10.2307 / 2325797

WILSON, T. J.; VALLE, M. R. DO. Estrutura de capital: o papel das fontes de financiamento nas quais as companhias abertas brasileiras se baseiam. São Paulo. Revista de Contabilidade e Finanças, v. 26, n. 69, /dez., 2015. http://dx.doi.org/10.1590/1808-057x201512130

WOOLDRIDGE, J. M. Introductory econometrics: a modern approach. 2. ed. [s.1.] MIT Press, 2002. 